\title{
Extensively Drug-Resistant Tuberculosis
}

National Cancer Institute

\section{Source}

National Cancer Institute. Extensively Drug-Resistant Tuberculosis. NCI Thesaurus. Code C128417.

Tuberculosis disease that is caused by an extensively drug-resistant strain of Mycobacterium tuberculosis. 